\title{
Evaluation on the Efficiency of Policy Implementation for Teacher Mobility of Compulsory Education between Rural and Urban Areas in China
}

\author{
Liu Xinzhi'1,2, Li Lu², Du Chunyan² \\ ${ }^{1}$ Agricultural Education Development Center of Southwest University, Chongqing, China \\ ${ }^{2}$ College of Economics and Management of Southwest University, Chongqing, China \\ Email: Liuxinzhi53@163.com, 1205041403@qq.com, 898234101@qq.com
}

Received 4 April 2014; revised 6 May 2014; accepted 13 May 2014

Copyright (C) 2014 by authors and Scientific Research Publishing Inc.

This work is licensed under the Creative Commons Attribution International License (CC BY). http://creativecommons.org/licenses/by/4.0/

\section{(c) (i) Open Access}

\begin{abstract}
The paper analyzes the policy implementation effect of the mobility of urban and rural teachers in the compulsory stage by using the data from $P$ province in China. We find that there are some problems in the process of the implementation of the teacher mobility policy, including passive attitude toward teachers, insufficient capital investment, ineffective implementation and so on. The main reason is that there is failure on the part of the government about government policy supply and the actual implementation. Based on this, we propose appropriate policy recommendations.
\end{abstract}

\section{Keywords}

Compulsory Education, Teacher Mobility, Equilibrium Development of Education, Government Failure

\section{Background: Teacher Mobility Is Pivotal to Promote Equilibrium Development of Compulsory Education in Urban and Rural Areas in China}

Fairness in education is fundamental and essential to a balance to be maintained between the developments of compulsory education in urban and rural areas. At present, China (in its mainland) is still in the primary stage of socialism with unbalanced social development and obvious dual structure between urban and rural areas, leading to inconsistent development of compulsory education and unevenly distribution of education resources in urban and rural areas, even in different regions and schools. Balanced development of urban and rural education is the 
key to the implementation and improvement of the overall strategy of basic education in the current and future periods, also it is in line with the content clearly mentioned in the Report to the Eighteenth National Congress of the Communist Party of China that rural education is the most important part and its new increasing education funding mainly devotes to rural places. The Ministry of Education requires each education sector to actively implement the teacher mobility policy, "making teacher resources as a whole and shaping teaching staff of rural schools and urban poor schools", in the "Opinions on further promoting balanced development of compulsory education”. "Long-term Education Reform and Development Plan (2010-2020)" points out: the fundamental measures of education fairness are the rational allocation of education resources especially for rural areas, remote poor areas and ethnic minority areas and narrowing education gap quickly. The main responsibility for education fairness is the government and the whole society should work together to promote education fairness. To effectively reduce the inter-school gap, we should take efforts to solve the problem of school choice, accelerating the transformation of poor schools, improving the quality of teachers and implementation of exchange system within teachers and principals in the county (district). Accordingly, all regions have made policies to promote compulsory education teacher mobility in urban and rural areas, which is beneficial for narrowing the gap between urban and rural compulsory education, actively improving school conditions in rural schools, and realizing balanced development of compulsory education.

Reasonable teacher mobility mainly refers to "the optimal allocation of resources within a certain range of teachers, so that their talent can make the best use" (Zhang Tianxue, 2010). But, what is an important factor affecting the flow of teachers? They can be physical compensation (wages, bonuses, allowances, pensions, etc.) and non-material remuneration, such as working conditions, work environment, personal accomplishment and student's socio-economic status (Greenberg \& McCall, 1973). Annegret Harnischfeger (1973) proposed characteristics of individual person, school, school location and region, and external factors can affect teacher mobility based on the large amount of data regression analysis (Harnischfeger, 1973). Other factors such as family time, administrative support and passion for the teaching are also involved in teacher mobility (Kersaint, 2007). Lots of proposals have been put forward for teacher mobility policy of urban and rural compulsory education, like the need to establish a flow system of primary and secondary teachers and the proposal that urban teachers go for teaching in the countryside, good teachers get sharing between rural and urban schools (Wu Songyuan, 2008). Wen Dai 闻待 (2009) analyzed the current situation and problems of Chinese teacher intercollegiate mobility policy with the help of policy tool framework, then gave some suggestions (Wen Dai, 2009).

Due to the insufficient information and policy implementation barriers, there may be some government failures in the implementation process. Government failure means the individual demand for public goods are not well satisfied to meet the recommendations in the modern democratic politics, and public sectors tend to waste and misuse resources in the provision of public goods, resulting in large-scale public spending or low efficiency, or the government made a decision with low economic efficiency (Buchanan) (Gregory Mankiw, 2011). Also government failure existed from education and teacher supply configuration (Zhang Xuemin, 2004; Xia Maolin \& Feng Wenquan, 2012). Although many scholars have studied the necessity, affecting factors and policymaking of teacher mobility of compulsory education in urban and rural areas, there is no in-depth analysis of problems of local government and teachers after the policy implementation. As the direct participant and stakeholder of teacher mobility policy, the sound of teachers should not be heard. From the teachers' point of view, the paper tries to find out current situation and problems of teachers after the implementation of mobility policies through fieldwork research by investigation, deeply analyzes reasons for government failure, and finally puts forward corresponding countermeasures.

\section{Evaluation: Empirical Investigation of the Effect of Teacher Mobility Policy Implementation}

This research takes teachers in compulsory education in P province as subjects with stratified random sampling, and randomly selects primary and secondary schools implemented urban and rural teacher mobility policy as samples. 300 questionnaires were distributed, in which 252 were valid in June and July, 2012.The basic information of the respondents are shown in Table 1.

\subsection{Comprehensive Evaluation of the Social Effects after Policy Implementation}

Fairness and balanced resources configuration are both important to help promote the integration of urban and 
Table 1. Basic information.

\begin{tabular}{|c|c|c|c|}
\hline \multicolumn{2}{|c|}{ Categories } & Number of people & Percentage \\
\hline \multirow{2}{*}{ Gender } & male & 70 & 27.78 \\
\hline & female & 182 & 72.22 \\
\hline \multirow{4}{*}{ Age } & $20-30$ & 22 & 8.73 \\
\hline & $31-40$ & 134 & 53.17 \\
\hline & $41-50$ & 86 & 34.13 \\
\hline & $51-60$ & 10 & 3.97 \\
\hline \multirow{5}{*}{ Working Years } & $1-5$ & 15 & 5.95 \\
\hline & $6-10$ & 43 & 17.06 \\
\hline & $11-15$ & 55 & 21.83 \\
\hline & $16-20$ & 70 & 27.78 \\
\hline & $20-30$ & 70 & 27.38 \\
\hline \multirow{3}{*}{ Position } & Teaching Management & 35 & 13.89 \\
\hline & Teaching & 214 & 84.92 \\
\hline & Other & 3 & 1.19 \\
\hline \multirow{4}{*}{ Title } & Senior & 33 & 13.10 \\
\hline & Intermediate & 118 & 46.83 \\
\hline & Junior & 85 & 33.73 \\
\hline & Unrated & 17 & 6.35 \\
\hline
\end{tabular}

rural education. Theoretically, mobility policy can guide and make urban teachers flow to rural areas, thus rural education will move into a higher ladder and the gap between urban and rural education will be narrowed down.

(1) Overall evaluation

Whether mobility policies promote efficient flow of rural and urban teachers, about $72 \%$ teachers held the view and $11 \%$ of them are on the opposite. Meanwhile, $63 \%$ teachers believe policies promote the balanced development of urban and rural education, and $18 \%$ is against this idea. Furthermore, $63 \%$ teachers insisted that the implementation of teacher mobility policy effectively promoted the integration of urban and rural education. Overall evaluation of teachers researched on rural teacher mobility policy is shown in Table 2. It can be seen from the overall evaluation of teachers, government policy implementation in urban and rural compulsory education is positive and urban and rural teachers' self-perception illustrates this point.

(2) Evaluation on the school

As the main participant, school is a platform of policy implementation. Thus, impacts and consequences of teacher mobility policy implementation on schools are pretty important. Most teachers believe the implementation of mobility policy effectively promotes the construction of teachers reasonably and enhances the overall quality of teachers and narrowing the gap among other schools, which make the school develop better than ever before. In contrast, about one-fifth of teachers expressed their opposition. Indeed, 39\% teachers state that the policy implementation affect teachers' normal teaching and school management; Meanwhile, $32 \%$ teachers notes the policy implementation undermines the interests of schools and teachers. Another one-third of teachers are not sure.

(3) Teachers' evaluation

Teachers are the direct participants in rural and urban mobility policy. So whether the policy is beneficial for teachers will directly affect their motivation involved in the mobility. Based on "economic man", teachers will search for marginal revenue maximization, which is bound to choose "reverse flow" (referring to teachers flow from rural primary and secondary school with poor resource to city schools with ample resources or even over, 
Table 2. Overall evaluation.

\begin{tabular}{|c|c|c|c|c|c|}
\hline Description & Total Agree & Agree & Uncertain & Disagree & Totally Disagree \\
\hline $\begin{array}{l}\text { Policy helps the efficient flow of resources } \\
\text { in urban and rural areas }\end{array}$ & $32.89 \%$ & $39.47 \%$ & $16.45 \%$ & $1.97 \%$ & $9.21 \%$ \\
\hline $\begin{array}{l}\text { Policy promotes equilibrium development of } \\
\text { urban and rural education }\end{array}$ & $32.89 \%$ & $30.26 \%$ & $19.08 \%$ & $5.92 \%$ & $11.84 \%$ \\
\hline $\begin{array}{l}\text { Policy implementation effectively furthers } \\
\text { the integration of urban and rural education }\end{array}$ & $34.87 \%$ & $28.29 \%$ & $19.74 \%$ & $5.26 \%$ & $11.84 \%$ \\
\hline
\end{tabular}

increasing the polarization of education resources). This is opposite to the "forward flow" of urban-rural teacher mobility policy. 55\% teachers think the policy implementation is inconvenience for their life; $49 \%$ teachers deny the fact that the policy implementation can increase revenue; $48 \%$ teachers do not believe that the policy implementation enhance their quality of life. Teachers' value get realization after the policy implementation, the pros and cons are $41 \%$ and $31 \%$ respectively. Visibly, teachers are seeking to maximize their own interests by demand-driven, most are dislike or even rebel the policy, which is in line with the previous analysis. These are quite serious, which have become major obstacles of the effective implementation of government policies.

(4) Evaluation on students

Students are the ultimate beneficiaries of the urban and rural teacher mobility policy. The starting point of policy-making aims at improving learning environment and the quality of students by teacher mobility. Only $32 \%$ teachers believe that the quality of students gets improved after teachers flowing into, while $28 \%$ teachers have expressed opposition. Only 33\% teachers admit the enrollment rate of students is higher than ever, while $26 \%$ of them are against it. $25 \%$ teachers claim that the situation of students going to the nearest school (not the city school) has no changes after policy implementation, while 37\% teachers oppose this point of view. Nearly $40 \%$ teachers maintain neutral, which means most schools embarked on teacher mobility policy just for a short time, the time of teacher mobility is limited (mostly 1 - 3 years), and advanced teaching methods and running ideas spread in schools also need time to verify and expand its influences, so the overall quality of students does not get a huge leap in the short term.

\subsection{Efficiency of Teacher Mobility Policy Implementation}

As we all know, efficiency is also another focus besides effectiveness in economics. Efficiency is the ratio of outputs and inputs, so we can pose an analysis of efficiency from two aspects. To meet the input demand of teacher mobility policy, government introduces policies, offers funding and other convenience, and human and resources investment of local schools. Through investigation, more than 35\% teachers believe that there is no enough investment from local governments and schools on teacher mobility money, human, and the others, and about $45 \%$ teachers keep uncertain, only about $20 \%$ teachers agree it. Reasons of such phenomena are as follows: First, some governments have not yet fully paid attention to the policy implementation and lack persistence in the capital, human, material resources investment; second, some governments and schools communicate with the outside world by information gap, which makes policy implementation details arouse suspicion and mistrust. With the policy implementation, inputs and outputs from the government and schools are not very good. Generally, the ration of teachers participating in the mobility is $1 \%-5 \%$. Only $22 \%$ teachers believe that investment from the local government has promoted teacher mobility effectively; and only $24 \%$ teachers think investment from school has promoted teacher mobility effectively.

As the above analysis, there are lots problems in the implementation, such as un-transparent government information, insufficient communication with the outside world, and misunderstanding of teachers to the motivation and purpose of implementation. So, more than half teachers evaluate the efficiency of policy with uncertainty.

\subsection{Social Satisfaction after the Policy Implementation}

Teachers are more sensitive to changes after policy implementation, so we should care more about teachers' evaluation. Table 3 highlights teachers' high satisfaction with "soft environment", which includes development trend, working environment and interpersonal relationships of inflow school, but when facing low satisfaction of welfare and career development, most teachers fall into uncertain. This shows that some local governments and 
Table 3. Satisfaction evaluation of teachers on policy.

\begin{tabular}{cccccc}
\hline Description & Totally Agree & Agree & Uncertain & Disagree & Totally Disagree \\
\hline $\begin{array}{c}\text { I'm satisfied with the current development } \\
\text { of inflow school after policy implementation }\end{array}$ & 27 & 65 & 109 & 20 & 31 \\
I'm satisfied with the working environment & $(10.53)$ & $(25.66)$ & $(43.42)$ & $(7.89)$ & $(12.30)$ \\
of inflow school after policy implementation & 18 & 70 & 110 & 27 & 27 \\
I'm satisfied with the interpersonal relationship & $(7.24)$ & $(27.63)$ & $(43.65)$ & $(10.53)$ & $(10.53)$ \\
of inflow school after policy implementation & $(6.35)$ & $(32.89)$ & $(40.79)$ & $(9.21)$ & $(10.53)$ \\
& 16 & 46 & 128 & 35 & 28 \\
I'm satisfied with the welfare of inflow school \\
after policy implementation
\end{tabular}

Note: The number in bracket is the proportion of the options.

schools did not make a good "soft environment" to help teachers get rid of barriers when they involve in mobility policy.

Students and parents are not quite satisfied with mobility policy from Figure 1 and Figure 2, most are uncertain. It seems that student mark is the only one they care and frequent mobility of teachers force students to constantly re-adjust to new teaching ideas and methods, which will directly affect students learning, therefore, teacher mobility often get less support for students and parents. In their view, the teacher mobility is "restless".

\subsection{Incentives and Fairness of Policy Implementation}

Figure 3 shows teachers' evaluation on incentive measures of policy implementation. We can see the number of teachers who are for and against incentive measures of policy implementation is both large. That's to say, the government does not take improved incentive measures into account when formulating and implementing policy, resulting in unclear effect.

Education fairness, social justices are common topics in public. Policy implementation aims to promote the teacher mobility in compulsory education and achieve education equity. 35\% teachers think their students enhance the sense of fairness and $28 \%$ of them held the opposite view after policy implementation, and another $37 \%$ is not clear. Nearly $41 \%$ teachers felt more equitable of education in urban and rural areas after policy implementation. From the above analysis, the current state doesn't match with the government's target of urban and rural teacher mobility and doesn't achieve the respected goal of public policy-fairness.

\section{The Key Problem: Government Failure}

By the above analysis, we find that teachers' feedback is far away from what the policy is expected to be. As the policy-maker and policy implementers, government is used to regulate the order and guide participants to realize periodic tasks and long-term goals. But for now, the role of government in promoting urban and rural teachers' mobility policy implementation is not obvious, reflecting certain failure in the following aspects.

\subsection{Unsound Teacher Mobility Policy System}

(1) Unreasonable material incentives system

Due to the uneven welfares of teachers in urban and rural areas, different intercollegiate and regions, teachers are bound to keep negative attitude towards teacher mobility policy in the light of their own interests. Since the local government and the school do not set specifically material incentives and subsidy systems or unreasonable systems for teachers who participate in the teacher mobility policy, it will not solve the real problems of teachers in reality and affect the policy implementation.

(2) Imperfect evaluation mechanism

There isn't a sound appraisal award system for teachers participating in the mobility policy. In consideration of material security, teachers will be more concerned about social recognition, and career development in the future. A fair evaluation environment and sound incentive mechanism can motivate each participating teacher involving in the mobility policy best. 


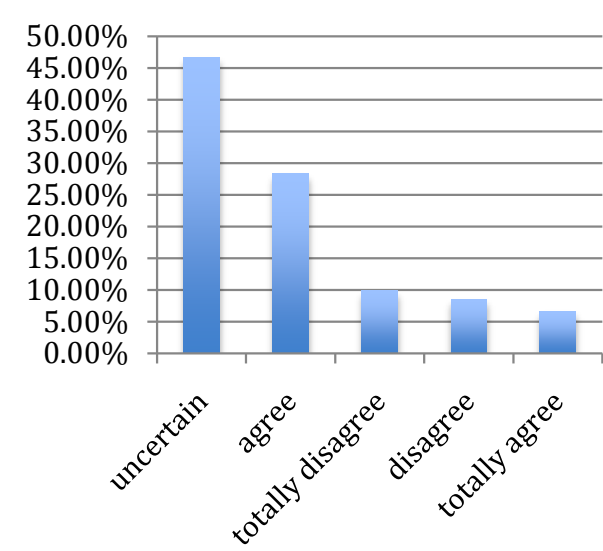

Figure 1. Satisfaction of parents to children learning.

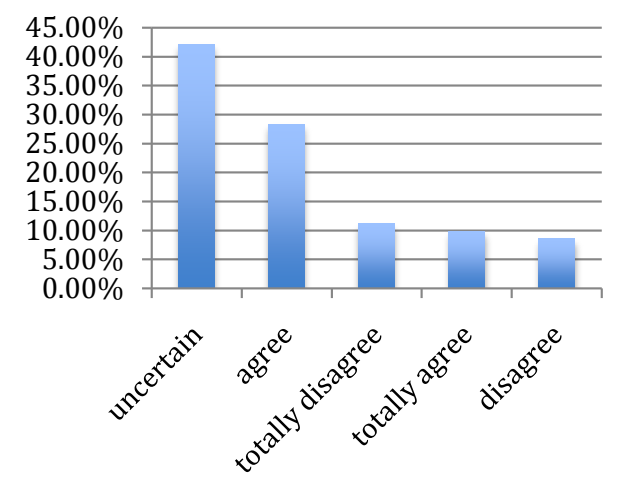

Figure 2. Satisfaction of students on teachers in inflow schools.

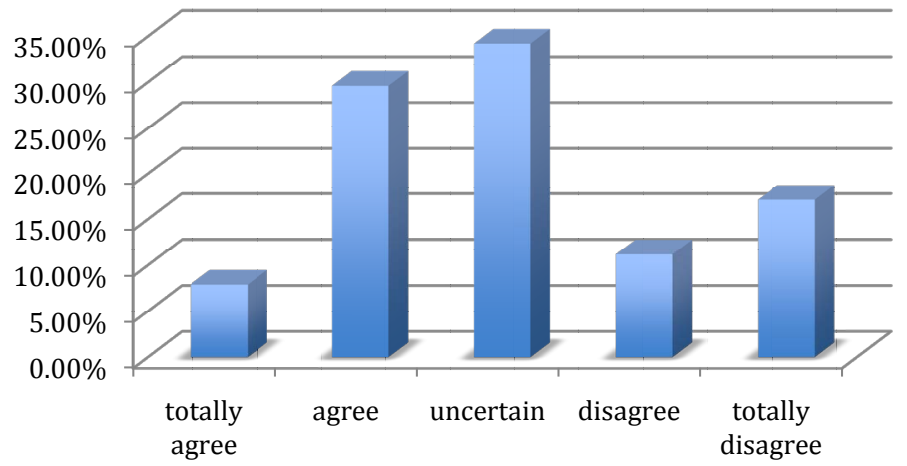

Figure 3. Teachers' evaluation on incentives.

(3) Unscientific post setting system

Post setting still restricts teachers' mobility. The reason is that some schools have fixed posts and the job over grade twelve in school is saturated. If a teacher once flows to other units, he or she may start from low-grade post since no absence of vacancy. Some teachers keep their own interests in mind, so they have to give up (especially teachers with high title) even though they want to flow.

\subsection{Lack of Strong Support from Local Government}

There needs to be great money and resources to achieve the goal of urban and rural teacher mobility policy. In fact, the small scale of teacher mobility and low mobile rate make the policy more symbolic than practical. Be- 
cause of short mobile time, teachers cannot adapt to the working environment in the new school and work well, which really cannot improve teaching quality and teachers' capability of the new school, and ultimately affect the realization of teacher mobility policy.

For education department, examination-oriented education system has not been changed. The enrollment rate is still the key to assessing performance of the local education department. To ensure a high enrollment rate, better schools and teachers are in demand. Teacher mobility policy will make the enrollment rate cannot be guaranteed or even decline over a long period of time. And local education department may not strive as much as possible for teacher mobility policy when considering performance.

\section{Solution: Recommendations for Enhancing the Effects of Policy Implementation}

Asymmetric information, bureaucracy and frequent policy changes led to the government failure in compulsory education policy. This phenomenon means the government tends to waste and misuse compulsory education resources and inefficient government interventions, which makes the education not meet the demand.

There are the following recommendations for problems in the implementation of teacher mobility policy: 1) constructing provision mechanism of super-elite cadres and teachers to make excellent development of schools, so as to good teachers can flow to rural schools; 2) selecting a group of young reserve cadres to go for temporary post in rural schools, and offering awards for cadres and their schools with good performance after the job ends, and taking it as one factor of promotion; 3) studying "regular flow" system from Japan (that is regular flow of schoolmaster and teachers every 3 - 5 years) to achieve teacher mobility comprehensively and consistently. Teacher mobility started with school leaders, followed by middle-level cadres, and then teachers. For those who meet the requirements of exchange but refuse to obey the exchange arrangement, the school must take strict measures, such as deposition of leaders and middle-level cadres, removing from teaching positions and relieving their duties and remuneration; 4) providing teachers with the opportunity of discussion, feedback and even participating in policy-making, so that teachers have the right and ability to protect their own interests; 5) incentives and evaluation mechanism should be established. The government should provide good teachers in poor schools with appropriate allowances; exchanges of teachers can be evaluated for titles and promotion; 6) teacher evaluation could gradually alter from current teaching experience to working experience of different schools, and establish mobility mechanism for schoolmasters and teachers in different schools to optimize educational resources; 7) strengthening contract management, which means that guiding and restraining teacher mobility must be in the form of contract, so that teacher mobility tends to be more reasonable and legal.

\section{Acknowledgements}

This paper is supported by Ministry of Education Science Project of Eleventh Five-Year Plan "Study on the Integration of Urban and Rural Vocational Education Resources and Its Path" (DJA090268); key project of important research base of Chongqing humanities and social sciences "Integration of Urban and Rural Vocational Education and Its Propulsion Mechanism” (11SKB36); Funds project of Central Universities Fundamental Research "Coordinated Development of Rural Education Agricultural Modernization in New Urbanization Process" (SWU1309375).

\section{References}

Greenberg, D. \& McCall, J. (1973). Theories of Teacher Mobility. A Report Prepared for the Office of Education, Washington DC, Report NO. P5098, 1-13.

Gregory Mankiw, N. (2011). Macroeconomics (the 7th ed.). Beijing: China Renmin University Press.

Harnischfeger, A. (1973) Personal and Institutional Characteristics Affecting Teacher Mobility. Paper Presented at Annual Meeting of the American Educational Research Association, New Orleans.

Kersaint, G., et al. (2007). Why Teachers Leave: Factors That Influence Retention and Resignation. Teaching and Teacher Education, 23, 775-794. http://dx.doi.org/10.1016/j.tate.2005.12.004

Wu Songyuan 吴松元 (2008). Zhong xiao xue jiaoshi liudong zhidu jianli de lixing sikao 中小学教师流动制度建立的理 性思考. Jiaoshi Jiaoyu Yanjiu, 4, 35-39.

Wen Dai 闻待 (2009). Jiaoshi xiaoji liudong zhengce de tansuo ji gaijin lujing 教师校际流动政策的探索及改进路径. 
Jiaoyu Fazhan Yanjiu, 10, 49-53.

Xia Maolin 夏茂林, \& Feng Wenquan 冯文全 (2012). Woguo yiwu jiaoyu shizi peizhi de lilun sikao 我国义务教育师资 配置的理论思考. Zhongguo Jiaoyu Xuekan, 3, 9-12.

Zhang Tianxue 张天雪 (2010). Jiaoshi Liudong: Jiyu Shizheng de Zhengce Fenxi 教师流动: 基于实证的政策分析. Harbin: Heilongjiang Jiaoyu Chubanshe.

Zhang Xuemin 张学敏 (2004). Lun jiaoyu gongji zhong de zhengfu shiling 论教育供给中的政府失灵. Gaodeng Jiaoyu Yanjiu, 1, 47-51. 